\title{
LA VIRTUALIDAD DE LA CUESTIÓN DE INCONSTITUCIONALIDAD EN LA PROTECCIÓN DE LOS DERECHOS DE LOS PARTICULARES
}

The virtues of the question of unconstitutionality in the protection of the rights of individuals

\author{
SILVIA ROMBOLI \\ Universidad Ramon Llull - ESADE \\ silvia.romboli@esade.edu
}

Como citar/Citation

Romboli, S. (2020).

La virtualidad de la cuestión de inconstitucionalidad en la protección de los derechos de los particulares. Anuario Iberoamericano de Justicia Constitucional, 24(1), 83-1 15. doi: https://doi.org/10.18042/cepc/aijc.24.03

\section{Resumen}

La cuestión de inconstitucionalidad, gracias a la virtuosa colaboración entre la jurisdicción ordinaria y la constitucional, ha sido un eficaz instrumento de depuración del ordenamiento jurídico de las normas con rango de ley contrarias a los contenidos de la Constitución. Junto con esa faceta «objetiva», este proceso constitucional ha demostrado su eficacia y sus potencialidades para ofrecer una efectiva protección de los derechos de los individuos. El presente trabajo tiene el propósito de destacar y visibilizar algunos de los principales elementos que plasman esa dimensión «subjetiva» de la cuestión de inconstitucionalidad.

\section{Palabras clave} derechos.

Jurisdicción constitucional; cuestión de inconstitucionalidad; protección de los

\section{Abstract}

The question of unconstitutionality, thanks to the virtuous collaboration between the ordinary and the constitutional jurisdiction, has been an effective instrument 
to eliminate unconstitutional norms from the legal system. Together with that «objective» facet, this constitutional process has demonstrated its effectiveness and potentialities to offer effective protection of the rights of individuals. The present work, therefore, has the purpose of highlighting and making visible some of the main elements that reflect that «subjective» dimension of the question of unconstitutionality.

\section{Keywords}

Constitutional jurisdiction; question of unconstitutionality; rights protection. 


\section{SUMARIO}

I. INTRODUCCIÓN. II. LAS FACULTADES DE ACTUACIÓN DE LAS PARTES ANTE LA JURISDICCIÓN ORDINARIA Y LA CONSTITUCIONAL: 1. El trámite de audiencia previa a las partes como único momento de "comunicación», antes de 2007, entre las partes del juicio a quo y el Tribunal Constitucional. 2. La condena del TEDH a España (caso Ruiz Mateos) y la consiguiente reforma de la LOTC de 2007 que abre las puertas del proceso ante el Tribunal Constitucional a las partes del proceso a quo. 3. Los efectos de la reforma de la LOTC de 2007 sobre el rol de las partes en el control de las leyes en vía incidental. III. LAS CONEXIONES ENTRE LA CUESTIÓN DE INCONSTITUCIONALIDAD Y EL RECURSO DE AMPARO CONSTITUCIONAL EN LA PROTECCIÓN DE LOS DERECHOS: LA ELECCIÓN DEL JUEZ A QUO DE NO PLANTEAR UNA CUESTIÓN Y LA POSIBILIDAD, EN CIERTOS CASOS, DE QUE ESTO VULNERE UN DERECHO FUNDAMENTAL: 1. Un primer supuesto. 2. Un segundo supuesto. El caso, muy específico, de la STC 58/2004: la vulneración de un derecho fundamental por exceso de jurisdicción, al no respetar el juez ordinario las características del sistema concentrado de justicia constitucional. IV. OTRA CLASE DE «INTERFERENCIAS» O CONEXIONES ENTRE LA CUESTIÓN DE INCONSTITUCIONALIDAD Y EL RECURSO DE AMPARO CONSTITUCIONAL EN LA PROTECCIÓN DE LOS DERECHOS: 1. Los efectos de la inconstitucionalidad de una ley declarada nula por sentencia recaída en una cuestión de inconstitucionalidad sobre los recursos de amparo en curso que traen origen de actos de aplicación de la ley anulada: la STC 159/1997 como pronunciamiento de referencia. 2. Los votos particulares a la STC 159/1997 y unas reflexiones a modo de síntesis. V. ALGUNAS CONSIDERACIONES CONCLUSIVAS. BIBLIOGRAFIA.

\section{INTRODUCCIÓN}

El sistema de justicia constitucional dibujado por la Constitución española de 1978 (CE, en adelante) se presenta, sin lugar a dudas, como uno de los más completos, respecto de las competencias y de las relativas modalidades de acceso al Tribunal Constitucional (TC, en adelante), ya desde sus orígenes ${ }^{1}$.

1 En efecto, la Constitución española incluye entre las competencias del Tribunal Constitucional el control de la constitucionalidad de las leyes y de los actos con fuerza de ley a través de la vía directa (art. 161.1 a) CE) y de la vía incidental (art. 163 CE), la 
Asimismo, gracias a la cláusula de cierre contenida en el art. 161.1 d) CE, según la cual el Tribunal Constitucional tendrá las competencias en «las demás materias que le atribuyan la Constitución o las leyes orgánicas», la Ley Orgánica del Tribunal Constitucional (LOTC, en adelante) ha ampliado a lo largo de los años estas competencias, incorporando, entre otras, la posibilidad de que los jueces y tribunales ordinarios enjuicien en vía prejudicial e incidental ante el TC la constitucionalidad de las Normas Forales fiscales de los Territorios de Álava, Guipúzcoa y Vizcaya ${ }^{2}$, o también que sea el TC quien se encargue, a petición de la parte legitimada para plantear el procedimiento correspondiente, de la ejecución de sus anteriores sentencias ${ }^{3}$.

A pesar de la multitud de vías de acceso al Tribunal Constitucional español, el procedimiento que con más frecuencia ha sido planteado ante él es, a todas luces, el recurso de amparo constitucional. Este procedimiento, como es notorio, permite, respetando diferentes requisitos formales, sustanciales y procesales, el acceso directo de los particulares a la jurisdicción constitucional, cuando estos consideren que un acto sin valor de ley emanado por un Poder Público haya vulnerado uno de sus derechos fundamentales o libertades públicas ${ }^{4}$.

Se trata, por lo tanto, de un tipo de procedimiento que tiene como finalidad patente la protección de los derechos e intereses del sujeto promotor del recurso y que tiene su origen en un acto concreto proveniente de un Poder Público que haya supuestamente violado un derecho o libertad fundamental de un individuos.

resolución de recursos de amparo por violación de los derechos y libertades reconocidos en los arts. 14-29 y 30.2 CE (art. 161.1 b) CE) y la solución de conflictos de competencia entre el Estado y las Comunidades Autónomas o de los de estas entre sí (art. 161.1 c CE). Otras constituciones europeas, por lo contrario, solo permiten algunos de estos procesos; puede pensarse, solo como ejemplo, en los sistemas italiano y francés de justicia constitucional, en los que los órganos correspondientes a nuestro TC solo pueden recibir cuestiones y recursos de inconstitucionalidad, pero con características y peculiaridades que restringen sensiblemente la posibilidad de su utilización. Por lo que concierne al sistema italiano, pueden consultarse, entre muchos otros, Ruggeri y Spadaro (2019), Zagrebelsky y Marcenò (2018); para el sistema francés se aconsejan Benvenuti (2016) y Cavino (2014).

2 Disposición adicional quinta, añadida por el art. 1 de la Ley Orgánica 1/2010, de 19 de febrero, de Reforma de la LOTC.

3 Art. 92 LOTC, modificado por el art. único 3 de la Ley Orgánica 15/2015, de 16 de octubre, de Reforma de la LOTC.

4 Art. 161.1 b) CE y arts. 41-58 LOTC.

5 El recurso de amparo constitucional puede ser planteado también por la vulneración de un derecho fundamental de una persona jurídica. 
Estas características, como es sabido, se contraponen claramente, según la doctrina mayoritaria, a aquellas de otros tipos de procesos constitucionales, como son los que tienen como objetivo el control de constitucionalidad de las normas con rango de ley. Se trataría de procedimientos cuya faceta, o dimensión, preponderante es la «objetiva», cuya pretensión capital se dirige a la eliminación del ordenamiento jurídico de las leyes inconstitucionales con la intención de preservar mejor la «autoridad» de la ley depurándola de cualquier vicio eventual.

Lo que se acaba de afirmar puede, sin duda, encajar perfectamente con el recurso de inconstitucionalidad. En cuanto a la cuestión de inconstitucionalidad, sin embargo, la doctrina se ha interrogado sobre su real naturaleza. A saber, si se trata de verdad de un recurso abstracto y objetivo o, por el contrario, de un recurso concreto, dado su origen en un caso específico. La conclusión, a la que adhiero, de algunos ilustres autores ${ }^{6}$ ha sido afirmar que estamos ante un procedimiento "híbrido», a saber, un proceso que incorpora elementos propios de una dimensión ciertamente objetiva en un proceso que tiene su origen en un supuesto absolutamente concreto y caracterizado por elementos e intereses subjetivos, y que, aunque de forma menos patente, tiene una dimensión «subjetiva» al garantizar, como se demostrará en estas páginas, la tutela y la efectividad de los derechos fundamentales ${ }^{7}$.

No obstante, por muchos años, la doctrina española se ha centrado únicamente en la dimensión objetiva, a saber, en la utilidad "final» y más evidente de la cuestión de inconstitucional, es decir en su aportación en la depuración del ordenamiento jurídico de las leyes o actos con fuerza de ley contrarios a los preceptos constitucionales. La dimensión subjetiva, o dicho en otras palabras, la virtualidad de la cuestión de inconstitucionalidad para la protección de los derechos e intereses de los individuos, ha pasado por lo tanto a un segundo plano, prácticamente invisible. Solo pocos autores, que han dedicado sus estudios expresamente a la cuestión de inconstitucionalidad, se habían percatado de dicha dualidad intrínseca a este proceso constitucional ${ }^{8}$.

6 López Ulla (2007: 199), Pérez Tremps (1985: 128 ss.). Pedro Cruz Villalón (1987: 43), de su lado, utilizó el término «impropio» para referirse a este proceso constitucional.

7 Asimismo, otra connotación que denota el carácter híbrido de este procedimiento constitucional es que el mismo, aunque pertenezca a un sistema de justicia constitucional concentrado, constituye un claro acercamiento a los modelos difusos. Véase, en este sentido, Fernández Segado (2005).

8 Entre otros, sin duda, Pérez Tremps (1985) y López Ulla (2000 y 2007). 
El propósito de este trabajo es, por lo tanto, visibilizar algunas de las características de la cuestión de inconstitucionalidad que demuestran la existencia, al lado de la dimensión objetiva, de una dimensión subjetiva capaz de dar voz a los derechos e intereses de los particulares. Una prueba de esto, es decir de la naturaleza concreta del control incidental de constitucionalidad de las leyes, tiene que buscarse, a todas luces, en el rol que la Norma Fundamental y la ley atribuyan a las partes ${ }^{9}$ del proceso a quo y a sus derechos e intereses.

Por consiguiente, será de especial interés analizar las posibilidades de actuación de las partes del juicio principal del que surge la cuestión de inconstitucionalidad, tanto en esa misma fase como en la fase ante el Tribunal Constitucional. A continuación, la investigación se centrará, de un lado, en el estudio de la protección de los individuos frente a la decisión del juez a quo de no plantear el control incidental de constitucionalidad (cuando la parte lo haya solicitado) y, de otro, en las posibles «interferencias» entre los efectos de las sentencias recaídas en los procesos de control incidental de constitucionalidad de las leyes y los recursos de amparo todavía en curso, para probar la efectiva proyección de los efectos de la cuestión de inconstitucionalidad en la protección de los derechos de los particulares.

9 La identificación de la noción de "parte» ante el juez ordinario no ofrece graves o significativos problemas de delimitación. La fase a quo del juicio incidental, en efecto, sigue obviamente las reglas de legitimación y personación propias del procedimiento de que se trate, que no suelen contar con disposiciones específicas que regulen el eventual planteamiento de una duda de constitucionalidad. Bajo esas circunstancias, la determinación de quien tenga que considerarse "parte» a los efectos de la regulación de la cuestión de inconstitucionalidad coincidirá con la atribución de dicha condición por las normas reguladoras de ese plano subjetivo en las leyes procesales adjetivas.

No obstante, para la jurisprudencia y la doctrina españolas ha planteado algunos interrogantes la determinación del concepto de "parte» al que se refiere el art. 35.1 y 2 LOTC, esto es, las consecuencias que pueden derivar de que se sigan las reglas del proceso específico en el que surja la duda de constitucionalidad y quede entonces confiada la especificación subjetiva al órgano judicial que conozca del supuesto concreto. Esta circunstancia podría suponer, efectivamente, una disminución en la tutela de los derechos de todos los sujetos verdaderamente involucrados, y esto porque, siendo esta apreciación prerrogativa del juez ordinario que plantee la cuestión de inconstitucionalidad, no se ha considerado posible «una revisión de la legalidad del procedimiento seguido para determinar si las partes en el proceso son las que realmente debieran serlo de acuerdo con la legislación vigente», STC 6/1984, de 24 de enero, FJ 1, comentada en Ribas Maura (1991: 56-57). 


\section{LAS FACULTADES DE ACTUACIÓN DE LAS PARTES ANTE LA JURISDICCIÓN ORDINARIA Y LA CONSTITUCIONAL}

\section{EL TRÁMITE DE AUDIENCIA PREVIA A LAS PARTES COMO ÚNICO MOMENTO DE «COMUNICACIÓN», ANTES DE 2007, ENTRE LAS PARTES DEL JUICIO A QUO Y EL TRIBUNAL CONSTITUCIONAL}

Si en la experiencia de otros países, la fase a quo del juicio incidental no contempla una participación trascendente (respecto del posible futuro planteamiento de una duda de constitucionalidad) de los particulares en ella involucrados, en España, de su lado, las partes del juicio ordinario pueden ya en esta primera etapa de la cuestión de inconstitucionalidad expresar sus alegaciones sobre las dudas que, en el caso de plantearse finalmente la cuestión, se sustanciarán en la fase que se deduce ante el Tribunal Constitucional.

Esta participación tiene su justificación en el hecho de que el sistema de justicia constitucional español no preveía la posibilidad de que las partes del proceso a quo participaran en la fase ad quem del juicio incidental de constitucionalidad de las leyes. Solo con la reforma de la LOTC operada por la LO 6/2007, de 24 de mayo, que se analizará a continuación, se introdujo esa facultad de comparecencia ante el Tribunal.

La precedente situación de indefensión (solo aparente, según parte de la doctrina ${ }^{10}$ ) resultaba amortiguada gracias a un expediente técnico que permitía - y sigue consintiendo- la intervención de las partes y del

10 Pueden leerse las observaciones, a este propósito, de Medina Guerrero (2000: 54 ss.). Villaverde Menéndez (2003: 257-258), al tratar la problemática relativa a la participación en la cuestión de inconstitucionalidad de las partes en el proceso a quo, afirma cuanto sigue: «Lo cierto es que desde la perspectiva aquí propuesta de la cuestión de inconstitucionalidad no hay razón alguna que imponga el emplazamiento de las partes en el proceso a quo o de quien pudiere tener un interés legítimo en el asunto. No se alcanza a ver la razón procesal o sustantiva que imponga esa audiencia en un proceso cuya finalidad es la depuración objetiva del ordenamiento jurídico en la que no se van a ventilar o discutir las pretensiones objeto del proceso de instancia. Además, este proceso constitucional tendría por objeto únicamente el examen de la convicción judicial sobre la inconstitucionalidad de la regla legal aplicable y decisiva del caso, extremo respecto del cual las partes ya se habrían defendido en el trámite de alegaciones previas del art. 35.2 LOTC, que es trasladado y conocido por el TC».

Sin embargo, otros ilustres autores habían sostenido la necesidad de una reforma de la regulación de la fase ad quem del control incidental de constitucionalidad de las leyes que permitiese la introducción de un contradictorio ante el TC, justo con la finalidad de proteger los derechos e intereses de las partes del proceso principal. Entre otros: 
Ministerio Fiscal en un momento anterior al planteamiento del incidente de constitucionalidad. Una fórmula que concreta un trámite de alegaciones, que sitúa a los sujetos del proceso ante una suerte de diálogo con la autoridad judicial ${ }^{11} \mathrm{y}$, sucesivamente (aunque indirectamente), con el Tribunal Constitucional.

El relieve de este momento procesal, denominado «trámite de audiencia previa», era particularmente intenso antes de la reforma de 2007 de la LOTC, encontrando su razón de ser en la vocación de dar voz a las consideraciones, intereses y derechos de los protagonistas del proceso judicial. De esta forma, como es obvio, se procura y atiende al carácter concreto de este tipo de proceso constitucional, recibiendo el Tribunal información sobre la utilidad y alcance que conllevará su decisión en el caso específico, prestada además directamente por los sujetos implicados en el mismo ${ }^{12}$.

Por la trascendencia de este trámite, típicamente español, se estima imprescindible examinar con detalle el rol y la posición de las partes en este momento procesal.

El art. 35.2 LOTC establecía en la versión legal original de 1979 que el juez ordinario, antes de elevar el auto de planteamiento, «oirá a las partes y al Ministerio Fiscal para que en el plazo común e improrrogable de 10 días puedan alegar lo que deseen sobre la pertinencia de plantear la cuestión de inconstitucionalidad; seguidamente y sin más trámite, el juez resolverá en el plazo de tres días».

López Ulla (2000), García Roca (1992: 121), Rubio Llorente y Aragón Reyes (1981: 836 y 863$)$.

11 Medina Guerrero (2000: 54) cita algunos autos del TC en los que se confirma el papel de instrumento de colaboración del trámite de audiencia (ATC 145/1993, de 4 de mayo, FJ 2), tanto en el sentido de que las alegaciones de las partes puedan servir al juez para razonar sobre la legitimidad constitucional de la norma en cuestión (ATC 185/1990, de 24 de abril, FJ 1) como para que el órgano proponente pueda delimitar mejor el objeto del planteamiento (ATC 875/1985, de 5 de diciembre, FJ 1).

12 El TC ha reiterado en múltiples ocasiones que: «El trámite de audiencia previa que establece el citado art. 35.2 de la LOTC, tiene el doble objetivo de garantizar la audiencia de las partes y del Ministerio Fiscal ante una decisión judicial de transcendencia, como es la de apertura de un proceso constitucional, y permitir, al mismo tiempo al Juez el conocimiento de la opinión de los interesados sobre esa decisión»; véanse, por ejemplo, entre las decisiones anteriores a la reforma de 2007: STC 42/1990, de 15 de marzo, FJ1; AATC 263/2006, de 4 de julio, FJ único; 299/2005, de 5 de julio, FJ 2; 308/2004, de 20 de julio, FJ 2; 367/2003, de 13 de noviembre, FJ 2; 242/2002, de 26 de noviembre, FJ 2. 
Esta regulación, que ha sido parcialmente modificada con la reforma de $2007^{13}$, ha dado lugar a un importante cuerpo doctrinal de interpretaciones del Tribunal Constitucional. Además de exteriorizar la finalidad del trámite de audiencia previa, al que ya se ha aludido hace un momento, la jurisprudencia constitucional precisa que esta fase procesal no constituye una actuación propia del proceso a quo, sino una etapa previa del posterior y eventual proceso ante el Constitucional ${ }^{14}$. Se define, por lo demás, como una condición procesal obligatoria, ya que su omisión produciría la cierta inadmisión de la cuestión ${ }^{15}$, por contradecir el art. 37.1 LOTC $^{16}$.

Por lo que incumbe a su forma y contenido, dicho trámite de audiencia previa tiene que iniciarse con una providencia que identifique las normas de cuya constitucionalidad se duda, los preceptos constitucionales que se consideran eventualmente violados y el razonamiento sobre esa sospecha de ilegitimidad constitucional. La jurisprudencia del Tribunal ha reiterado de manera permanente e insistente la necesidad de que todos estos contenidos estén suficientemente identificados ante las partes y el Ministerio Fiscal, si bien acepta una exposición escueta o sucinta de los mismos ${ }^{17}$. El Tribunal atribuye y reconoce a este trámite la función de delimitar el contenido del eventual y sucesivo auto de planteamiento ${ }^{18}$, llegando a inadmitir aquellas cuestiones de inconstitucionalidad en las que la providencia que activa la audiencia previa se haya demostrado imprecisa e insuficiente para permitir a las partes conocer

13 La reforma ha añadido la posibilidad que las partes aleguen también sobre el fondo de la cuestión de inconstitucionalidad. El art. 35.2 LOTC, en su nueva redacción, establece que el juez ordinario, antes de elevar el Auto de planteamiento, «oirá a las partes y al Ministerio Fiscal para que en el plazo común e improrrogable de 10 días puedan alegar lo que deseen sobre la pertinencia de plantear la cuestión de inconstitucionalidad, o sobre el fondo de ésta».

14 ATC 108/1993, de 30 de marzo, FJ 2 b).

15 Pueden verse, entre otras decisiones: STC 166/1986, de 19 de diciembre, FJ 4; AATC 113/2019, de 1 de octubre, FJ 3 a); 6/2017, de 18 de enero, FJ 2; 295/2006, de 26 de julio, FJ 1; 164/2006, de 9 de mayo, FJ único; 102/2003, de 25 de marzo, FJ 2; 199/2001, de 4 de julio, FJ 1; 265/2000, de 14 de noviembre, FJ 2; 152/2000, de 13 de junio, FJ 2; 136/1995, de 9 de mayo, FJ único.

16 El TC ha afirmado reiteradamente en la jurisprudencia citada en estas páginas que el correcto cumplimiento del trámite de audiencia previa tiene que considerarse uno de los requisitos procesales exigidos ex art. 37.1 LOTC. Pueden consultarse, por ejemplo, los AATC 113/2019, de 1 de octubre, FJ 2; 156/2016, de 20 de septiembre, FJ 3 a).

17 Entre otras, STC 50/2015, de 5 de marzo, FJ 2.

18 Además de consultarse los trabajos más generales respecto de la cuestión de inconstitucionalidad, en relación con el auto de planteamiento véase Viver Pi-Sunyer (1999). 
los argumentos que fundaban el planteamiento de la cuestión ${ }^{19}$. De otro lado, aunque en algunas ocasiones el Tribunal Constitucional haya estimado que la omisión de uno de estos datos supone una simple irregularidad y no tiene necesariamente que conducir a una decisión de inadmisión ${ }^{20}$, en muchas otras ha inadmitido cuestiones de inconstitucionalidad (o partes de ellas) porque el auto de planteamiento añadía contenidos novedosos respecto de los formulados en el trámite de audiencia previamente desarrollado (sea otra norma objeto del control de constitucionalidad o sea otra disposición constitucional parámetro de dicho control), al no haber podido ser objeto de consideraciones $\mathrm{y}$ alegaciones de las partes y del Ministerio Fiscal ${ }^{21}$.

\section{LA CONDENA DEL TEDH A ESPAÑA (CASO RUIZ MATEOS) Y LA CONSIGUIENTE REFORMA DE LA LOTC DE 2007 QUE ABRE LAS PUERTAS DEL PROCESO ANTE EL TRIBUNAL CONSTITUCIONAL A LAS PARTES DEL PROCESO A QUO}

Como ya hemos apuntado, una parte de la doctrina española había manifestado su desacuerdo con la regulación orgánica que no contemplaba la personación de las partes en el juicio ad quem, reputando insuficientes las garantías proporcionadas a través del trámite de audiencia del art. 35 LOTC ${ }^{22}$.

Sin embargo, no fueron las sugerencias de ilustres autores las que impulsaron al legislador español a modificar la LOTC, sino más bien las consecuencias que derivaron de una decisión del Tribunal Europeo de Derechos Humanos (TEDH, en adelante) que condenó a España, entre otras razones, por negar a ciertos sujetos la participación en el proceso ante el TC con ocasión de una cuestión de inconstitucionalidad.

La trascendencia del caso, muy notorio en España, hace oportuno dedicar unas palabras al resumen de lo sucedido ${ }^{23}$. El Juzgado de Primera Instancia núm. 18 de Madrid promovió una cuestión de inconstitucionalidad en

19 Acerca de los requisitos de admisión de las cuestiones de inconstitucionalidad: González Jiménez (1996).

20 Por ejemplo, puede verse la STC 166/1986, de 19 de diciembre, FJ 4.

21 Entre las decisiones posteriores a la reforma de 2007, pueden citarse, en este sentido: SSTC 72/2017, de 5 de junio, FJ 1 a); 95/2015, de 14 de mayo, FJ 2 y 50/2015 de 5 de marzo, FJ 2 b); AATC 142/2016, de 19 de julio, FJ 2; 83/2016, de 26 de abril, FJ 2.

22 Como ya se ha evidenciado en la nota 10 , pueden mencionarse, entre otros: López Ulla (2000), García Roca (1992: 121), Rubio Llorente y Aragón Reyes (1981: 836 y 863).

23 Es posible encontrar un comentario a este caso y a sus repercusiones en el ordenamiento jurídico español en Vidal Fueyo (2013: 131-152). 
relación con determinados artículos de la Ley 7/1983, de 29 de junio, sobre «expropiación por razones de utilidad pública e interés social de los Bancos y otras sociedades que componen el grupo "Rumasa, Sociedad Anónima»", a instancia de uno de los afectados por la aplicación de la mencionada ley singular, don José María Ruiz Mateos y Jiménez de Tejada. Las características de la expropiación, y en particular el hecho de ser ordenada a través de una ley singular, habían imposibilitado la defensa de los sujetos destinatarios de la medida, pues no tenían la posibilidad de instar un recurso contencioso-administrativo, ni de recurrir en amparo ante el Tribunal Constitucional, al no ser idóneo ese proceso constitucional para la impugnación directa de leyes. La cuestión, cuyo planteamiento se fundó en la vulneración del derecho fundamental a la tutela judicial efectiva (art. $24 \mathrm{CE}$ ), fue desestimada por el Constitucional en la STC 166/1986, de 19 de diciembre.

La duda de legitimidad constitucional de la misma ley singular volvió a plantearse con una segunda cuestión de inconstitucionalidad, esta vez por vulneración de los arts. 14 (principio de igualdad ante la ley) y $33.3 \mathrm{CE}$ (límites al derecho a la propiedad), que el Alto Tribunal desestimó nuevamente, ahora en la STC 6/1991, de 15 de enero. En ambas ocasiones, así como estaba previsto en la regulación española, las partes no pudieron personarse ante el Constitucional en la fase ad quem.

Los sujetos afectados por la expropiación recurrieron, entonces, ante el Tribunal Europeo de Derechos Humanos, por vulneración del art. 6.1 del Convenio (derecho a un proceso equitativo), alegando la excesiva duración del proceso y la violación del derecho de defensa, en razón de la imposibilidad de participar en el contradictorio. El Tribunal Europeo condenó a España en la Sentencia de 23 de junio de 1993, asunto Ruiz Mateos c. España, por vulneración del artículo mencionado. Las fundamentaciones de la condena del TEDH se detienen, de un lado, en la efectiva duración excesiva del proceso, y, de otra parte, en la vulneración del derecho de defensa de Ruiz Mateos. Sobre este último tema, el Tribunal de Estrasburgo nada dijo que alcanzara a la normativa española referida al acceso o personación de las partes procesales ante el Tribunal Constitucional con ocasión de una cuestión de inconstitucionalidad (semejantes valoraciones, seguramente, habrían constituido una injerencia indebida en las potestades del Estado español, no dejando espacio a aquel legítimo margen de apreciación nacional que las instituciones supranacionales tienen la obligación de respetar $\left.{ }^{24}\right)$. Pese a ello, y no obstante ese límite, el Tribunal de Estrasburgo sí que percibió la peculiaridad del caso, señaladamente al ser de aplicación una ley singular, y advirtió cómo los destinatarios

24 Sobre el margen de apreciación nacional, entre otros: García Roca (2010 y 2007). 
no habían tenido la posibilidad de defenderse a través de un contradictorio ${ }^{25}$. Bajo esas circunstancias, resolvió que si el caso tiene como objeto «una ley que concierne directamente a un círculo restringido de personas» $\mathrm{y}$ "la cuestión de constitucionalidad de la ley es deferida al Tribunal Constitucional en el marco de un procedimiento relativo a un derecho de carácter civil y en el que son partes sujetos que pertenecen al susodicho círculo, es necesario en principio garantizarles el libre acceso a las observaciones de las demás partes y una real posibilidad de comentarlas» ante el Tribunal Constitucional mismo ${ }^{26}$.

La decisión de la Corte europea se dirigía así, por consiguiente, a consagrar o estimular la participación en la fase procesal ante el Constitucional de los sujetos destinatarios de una ley singular, siquiera cuando hubiesen actuado como partes en el proceso principal en el que traía origen la cuestión de inconstitucionalidad. Es importante enfatizar lo anterior (nos referimos a las peculiaridades de este caso concreto y las consideraciones, fundadas en ellas, del Tribunal de Estrasburgo) para entender las sucesivas actuaciones del Tribunal Constitucional, que rechazó las solicitudes de quienes querían personarse en el proceso ad quem fundando tal pretensión en la necesaria aplicación de la jurisprudencia del $\mathrm{TEDH}^{27}$.

\section{LOS EFECTOS DE LA REFORMA DE LA LOTC DE 2007 SOBRE EL ROL DE LAS PARTES EN EL CONTROL DE LAS LEYES EN VÍA INCIDENTAL}

Como se ha mencionado justo antes de empezar a analizar el caso Ruiz Mateos, probablemente la razón principal que ha determinado la modificación del régimen de personación ante el Tribunal Constitucional en las cuestiones de inconstitucionalidad se encuentra en esa sentencia del Tribunal de Estrasburgo de 23 de junio de 1993. Es la misma Ley Orgánica 6/2007, de 24 de mayo, por la que se modifica la Ley Orgánica 2/1979, de

25 Para un estudio más detallado acerca de la jurisprudencia constitucional en materia de control de leyes singulares (incluido el análisis del caso Rumasa), véase el trabajo de Requejo Rodríguez (2015: 5-12).

26 Sentencia de 23 de junio de 1993, asunto Ruiz Mateos c. España, n. 63.

27 El Tribunal, como consecuencia de la sentencia del TEDH sobre el caso Ruiz Mateos, recibió varias solicitudes de personación de las partes de procesos a quibus en los que se plantearon CCI; véanse, por ejemplo, los AATC 260/2003, de 15 de julio; 239/1999, de 13 de octubre; 178/1996, de 26 de junio. Para un análisis doctrinal de las consecuencias de la decisión del TEDH en la jurisprudencia del Tribunal Constitucional puede verse Castellá Andreu y Expósito Gómez (1999). En general, sobre el caso, resultan muy interesantes también los trabajos de Escobar Fernández (1993), Gallardo Castillo (1994) y Montilla Martos (1994). 
3 de octubre, del Tribunal Constitucional, la que en su tercera exposición de motivos lo confirma:

La [presente] ley intensifica el papel de las partes litigantes del proceso judicial en el que se plantee una cuestión de inconstitucionalidad, ya que no sólo se les permite realizar alegaciones sobre la pertinencia de plantear la cuestión de inconstitucionalidad, sino que también se permiten alegaciones sobre el fondo de la cuestión. $\mathrm{Al}$ tiempo, se introduce la posibilidad de personación de los litigantes del proceso judicial ante el Tribunal Constitucional en los 15 días siguientes a la publicación en el 'Boletín Oficial del Estado' de la admisión a trámite de las cuestiones de inconstitucionalidad, para permitir la contradicción en este procedimiento de constitucionalidad, siguiendo en esto las directrices contenidas en la Sentencia de 23 de junio de 1993, del Tribunal Europeo de Derechos Humanos.

Sea como fuere interpretada la intrahistoria del cambio legislativo, cinéndose ahora a las modificaciones normativas de la disciplina del contradictorio durante la fase ad quem, se comprueba que la nueva redacción legal añade, de un lado, un inciso en el art. 35.2 LOTC por el que las partes del proceso a quo podrán alegar sobre el fondo de la cuestión en el trámite de audiencia previa $y$, de otro, un nuevo apartado segundo al art. 37 LOTC (pasando el antiguo segundo a tercero), que tiene la siguiente redacción: «Publicada en el "Boletín Oficial del Estado" la admisión a trámite de la cuestión de inconstitucionalidad, quienes sean parte en el procedimiento judicial podrán personarse ante el Tribunal Constitucional dentro de los 15 días siguientes a su publicación, para formular alegaciones, en el plazo de otros 15 días».

La reforma, en cambio, y es esta una de las circunstancias que se quieren remarcar por su conexión directa con las finalidades de este trabajo, no ha tenido como efecto la modificación de la doctrina del Tribunal Constitucional sobre el valor del trámite de audiencia previa a las partes y al Ministerio Fiscal (art. 35 LOTC). Podría pensarse que en el nuevo sistema jurídico trazado por la LO 6/2007 dicha audiencia previa, ante el juez a quo, pueda perder el papel cardinal que venía anteriormente a desempeñar, dado que ahora las partes pueden presentar sus consideraciones directamente al Constitucional.

Esto no es óbice, no obstante, para que el Tribunal siga manteniendo sus criterios previos sobre el particular, considerando el trámite de audiencia del art. 35 LOTC como un momento primordial del procedimiento que revisa con detalle en el juicio de admisibilidad de la cuestión de inconstitucionalidad, además de un «requisito de todo punto inexcusable, cuya eventual omisión constituye un defecto en el modo de proposición de la cuestión que ha de determinar, tras el trámite previsto en el art. 37.1 LOTC, la inadmisión 
de la cuestión así suscitada ${ }^{28}$. Esa posición responde, a mi criterio y acorde con la jurisprudencia constitucional, a la distinta finalidad que cumplen los dos momentos con los que cuentan las partes para formular alegaciones. En el momento previo al planteamiento de la cuestión, el objetivo de su intervención no es exclusivamente garantizar que tengan eco sus intereses subjetivos, sino también que el órgano judicial reciba las consideraciones y valoraciones de los involucrados en el litigio para poder decidir sobre la conveniencia o no del planteamiento de la duda de constitucionalidad. Aunque no excluya por supuesto la motivación de constitucionalidad, la audiencia tiene, así, un valor ligado a la defensa de la oportunidad o impropiedad de instar el procedimiento. El destinatario de las alegaciones es entonces el juez a quo, de modo que solo indirectamente las opiniones de las partes llegarán al Tribunal Constitucional reproducidas en el auto de planteamiento.

La nueva fase de audiencia a las partes durante el proceso ad quem, por contra, constituye el escenario en el que los directamente afectados en el proceso judicial muestran sus razonamientos de constitucionalidad al Alto Tribunal. Tiene esta segunda «audiencia», así, un valor estrictamente argumentativo, ligado al juicio sustantivo de constitucionalidad, por más que nada impida a las partes argumentar, por ser razón y fundamento de su intervención ante el Tribunal, sobre las concretas circunstancias del caso enjuiciado en el proceso a quo que resulten atravesadas por la respuesta que la cuestión vaya a merecer en el pronunciamiento del Tribunal.

\section{LAS CONEXIONES ENTRE LA CUESTIÓN DE INCONSTITUCIONALIDAD Y EL RECURSO DE AMPARO CONSTITUCIONAL EN LA PROTECCIÓN DE LOS DERECHOS: LA ELECCIÓN DEL JUEZ A QUO DE NO PLANTEAR UNA CUESTIÓN Y LA POSIBILIDAD, EN CIERTOS CASOS, DE QUE ESTO VULNERE UN DERECHO FUNDAMENTAL}

\section{UN PRIMER SUPUESTO}

Otros de los temas de mayor calado concernientes al análisis de la cuestión de inconstitucionalidad en su vertiente subjetiva, a saber, como

28 ATC 156/2016, de 20 de septiembre, FJ 3 a). Pueden consultarse también las SSTC 95/2015, de 16 de mayo, y 50/2015, de 5 de marzo, y los AATC 83/2016, de 26 de abril; 73/2016, de 12 de abril; 36/2016, de 16 de febrero, y 113/2019, de 1 de octubre. 
instrumento de tutela de derechos, es el debate que gravita alrededor de una eventual obligatoriedad del planteamiento de la cuestión por parte del juez ordinario si una de las partes del proceso lo solicitase ${ }^{29}$. Aunque, véase, para ser más concretos: el punto crucial sobre el que la doctrina y la jurisprudencia española se interrogaron radica en la posibilidad de que la decisión del órgano judicial de rechazar el planteamiento de una cuestión pudiese llevarse a cabo sin motivación y, sobre todo, si en esa hipótesis se causaba o no la vulneración del derecho a la tutela judicial efectiva (art. 24.1 CE) del sujeto que había solicitado elevar la duda de constitucionalidad ante el Constitucional.

Desde el principio de su funcionamiento, el Tribunal Constitucional consideró que la decisión sobre la promoción de este tipo de proceso constitucional es una manifestación de la que se puede definir, utilizando las palabras de Jiménez Campo (1998: 94), como «autodeterminación judicial». Plantear o no una duda de constitucionalidad ante el Constitucional es decisión, por tanto, que compete en exclusiva al órgano judicial que conoce del caso específico; una prerrogativa exclusiva e irrevisable del juez ordinario ${ }^{30}$. Es más, para el Alto Tribunal, incluso en un escenario en el que una de las partes del proceso hubiera mostrado su incertidumbre sobre la legitimidad constitucional de la norma aplicable al mismo, la negativa a suscitar la cuestión por parte del juez no vulneraría por sí sola el derecho ex art. $24 \mathrm{CE}$. Llegó más lejos aún en el discurrir de su jurisprudencia, acogiendo una conclusión más rotunda: tan amplia es la libertad del juez ordinario en esta decisión que no conculcaría el derecho fundamental a la tutela judicial efectiva ni siquiera la falta de

29 La normativa establece que la cuestión de inconstitucionalidad pueda solicitarse a instancia de parte o de oficio. Sin embargo, se verá a continuación que el planteamiento de la cuestión depende exclusivamente de la voluntad del órgano judicial, y que a raíz de esta circunstancia pueden surgir distintas problemáticas. Véase el art. 35 LOTC.

Corzo Sosa (1998: 316 ss.), en contra de la mayoría de la doctrina y de quien escribe, estima que las partes tienen un derecho subjetivo al planteamiento. De esta forma, el hecho de que el juez decida de forma completamente autónoma sobre el planteamiento, podría terminar por no dar el justo espacio a los intereses de las partes, alejando la cuestión de inconstitucionalidad de su dimensión subjetiva.

30 Entre muchos otros ejemplos, pueden citarse: SSTC 22/2018, de 5 de marzo, FJ 5; 129/2013, de 4 de junio, FJ 6; AATC 126/2017, de 20 de septiembre, FJ 2 b); 56/2011, de 18 de mayo, FJ 2.

Sobre el particular, Herrero-Tejedor (2000: 22-25) afirma que las partes tienen una «mera facultad de instar el planteamiento de la cuestión» que, como mucho, puede derivar de un interés legítimo en que su caso se resuelva aplicando una ley conforme con la Constitución. Acerca de esta temática, véanse también López-Fragoso Álvarez (1991) y Pérez Gordo (1980). 
motivación y justificación del no planteamiento de la cuestión en la sentencia que cierra el juicio en cuestión ${ }^{31}$.

En la jurisprudencia más reciente, sin embargo, el Tribunal Constitucional ha modificado su doctrina. Aunque manteniendo idénticas sus previas afirmaciones sobre la exclusiva prerrogativa judicial en la decisión de plantear o no la cuestión de inconstitucionalidad, ha declarado con reiteración que la falta de motivación, o incluso una motivación que se manifieste incoherente o arbitraria al disponer no elevar la duda de constitucionalidad, sí constituye una vulneración del derecho a la tutela judicial efectiva ${ }^{32}$.

\section{UN SEGUNDO SUPUESTO. EL CASO, MUY ESPECÍFICO, DE LA STC 58/2004: LA VULNERACIÓN DE UN DERECHO FUNDAMENTAL POR EXCESO DE JURISDICCIÓN, AL NO RESPETAR EL JUEZ ORDINARIO LAS CARACTERÍSTICAS DEL SISTEMA CONCENTRADO DE JUSTICIA CONSTITUCIONAL}

Absolutamente distintiva es la doctrina que fija la STC 58/2004, de 19 de abril, que puede considerarse uno de los pronunciamientos principales en este tema.

Será preciso, siquiera de modo panorámico, describir el supuesto de hecho. Un empresario del sector del juego presentó un escrito dirigido al jefe de la Sección del Juego de la Delegación Territorial de Barcelona (Generalidad de Cataluña) oponiéndose a la tasa fiscal que le correspondía abonar según lo dispuesto en el art. 38.2.1 de la Ley 5/1990, de 29 de junio, así como, en segundo lugar, contra el recargo autonómico establecido sobre la misma por una Ley del Parlamento de Cataluña, la 2/1987, de 5 de enero, y los incrementos establecidos en aquella en sucesivas leyes presupuestarias de diversos ejercicios. Desestimada esa oposición y efectuada la liquidación correspondiente, el interesado presentó una reclamación económico-administrativa, que fue también rechazada, y seguidamente un recurso contencioso-administrativo, que resultó en cambio estimado por la Sala de lo Contencioso-Administrativo del Tribunal Superior de Justicia

31 Puede leerse, en este sentido, el FJ 1 del ATC 767/1986, de 8 de octubre.

32 Entre otras sentencias, en este sentido: SSTC 263/2015, de 14 de diciembre, FJ 2; 35/2002, de 11 de febrero, FJ 3.

En doctrina, para un estudio específico sobre la vulneración del derecho ex art. 24 CE de las partes del proceso en caso de no planteamiento de una cuestión de inconstitucionalidad, véase Requejo Rodríguez (2015). La autora, sin embargo, llega a la conclusión de que la falta de una respuesta motivada, razonable y suficiente por parte del órgano judicial que recibe la instancia de parte, no supone la violación del derecho a la tutela judicial efectiva (Requejo Rodríguez, 2015: 3-4). 
de Cataluña, anulando la resolución impugnada por no ser conforme a derecho y declarando el derecho de la recurrente a la devolución de las cantidades indebidamente ingresadas. Para sostener su interpretación, el órgano judicial citaba la declaración de inconstitucionalidad contenida en la STC 173/1996, de 31 de octubre, que quedó referida al art. 38.2.2 de la Ley 5/1990, de 29 de junio, que incrementaba la cuota anual de la citada tasa para un concreto ejercicio (1990). Igualmente, ahora para analizar «la legalidad del recargo autonómico», establecido en la ley autonómica antes citada, el órgano judicial examina la legalidad de la tasa a la luz de la Sentencia de 26 de junio de 1997 del Tribunal de Justicia de las Comunidades, al examinar las cuestiones afectantes a la tutela, delimitación y limitación del contenido esencial de los derechos fundamentales y su eficacia en los ámbitos de protección multinivel.

En el recurso de amparo promovido por la Generalidad de Cataluña se ponían en cuestión los dos pronunciamientos de la sentencia impugnada, tanto el correspondiente a la tasa estatal como el propio del recargo autonómico. La fundamentación esencial residía, desde ambos prismas, en la existencia de una desatención del sistema de fuentes, con lesión del art. 24 CE.

El pronunciamiento tiene relevancia al objeto que en este momento se analiza en razón de que la decisión adoptada por el órgano judicial sobre la tasa prescrita en el art. 38.2.1 de la Ley 5/1990, de 29 de junio, que acuerda no aplicar al caso por su (pretendida) contradicción con la Norma Fundamental, se produjo sin planteamiento de una cuestión de inconstitucionalidad ante el Constitucional. Dice el Tribunal en la STC 58/2004 que el apartado del fallo que se funda en una pretendida inconstitucionalidad de la tasa fiscal fijada por el art. 38.2.1 de la Ley 5/1990 no es correcto, pues no fue esa declaración la que hizo la STC 173/1996, de 31 de octubre, referida exclusivamente al art. 38.2.2 de la Ley (un gravamen complementario aplicable exclusivamente durante un ejercicio, el año 1990) y no al art. 38.2.1 (cuota de la tasa), que ahora resultaba objeto de la controversia. Esto así, afirma: «(e)llo supone que, al extender el órgano judicial los efectos de nuestra declaración de inconstitucionalidad hecha para una figura tributaria (el gravamen complementario) a otra totalmente distinta (la tasa fiscal del juego), se está arrogando una competencia que no le corresponde, incurriendo, también en este caso, en un exceso de jurisdicción».

A fin de fundamentar esa conclusión, recuerda la sentencia constitucional que el Constituyente ha querido sustraer al juez ordinario la posibilidad de inaplicar una ley con base en un juicio de incompatibilidad con la Constitución; que la depuración del ordenamiento legal, vigente la Constitución, corresponde de forma exclusiva al Tribunal Constitucional y, asimismo, que la disposición de ley que, según el juzgador, resulte aplicable en el proceso no puede dejar de serlo, por causa de su posible invalidez, sino a través de la 
promoción de una cuestión de inconstitucionalidad mediante resolución motivada (art. $163 \mathrm{CE}$ ) y con la audiencia previa que prescribe el art. 35 LOTC.

Concluyendo de todo lo dicho: «ignorar estas reglas, constitucionales y legales, supone, en definitiva, no sólo menoscabar la posición ordinamental de la ley en nuestro Derecho y soslayar su singular régimen de control, sino privar también al justiciable de las garantías procedimentales (como el de la previa audiencia, a que nos acabamos de referir), sin cuyo respeto y cumplimiento la ley aplicable al caso no puede dejar de ser, en ningún supuesto, inaplicada o preterida", lesionándose en otro caso, termina el pronunciamiento, el derecho a un proceso con todas las garantías (art. 24.2 CE) en el supuesto concreto: «tanto por no haber planteado el órgano judicial la cuestión de inconstitucionalidad prevista en el art. $163 \mathrm{CE}$, única vía que le asistía para dejar inaplicada la norma con rango legal aplicable al supuesto de autos, como por haber desconocido la eficacia de una norma legal plenamente vigente», y también el art. 24.1 CE (por negar el derecho de defensa del interesado, que no tuvo «oportunidad u ocasión de prever tal preterición, dado el sometimiento judicial al imperio de la ley, ni pudo hacer uso del trámite de alegaciones previsto en el art. 35 LOTC»).

Es interesante destacar que, así como el Tribunal ha insistido mucho en que no hay vulneración del art. $24 \mathrm{CE}$ por la decisión motivada de no planteamiento de una cuestión de inconstitucionalidad por parte del órgano judicial, cerrando de esa manera la hipótesis de que las peticiones formuladas en ese sentido a instancia de parte puedan acarrear una quiebra de derechos fundamentales cuando sí son rechazadas, así también, en cambio, la lesión se da (a modo de excepción a aquella regla general) cuando el no planteamiento de la cuestión va acompañado de un exceso de jurisdicción. Esto es, lo determinante de uno u otro resultado es la efectiva aplicación de la ley al caso, ya que solo puede evitarse tras una declaración de inconstitucionalidad adoptada por el Tribunal Constitucional.

Un criterio que no puede sino parecer razonable, pues es obvio que en el diseño español la decisión de planteamiento corresponde al juez ordinario, pero que, del mismo modo, este no puede convertir ese margen apreciativo en un resultado de desatención de la ley por inconstitucionalidad, eludiendo los límites de su jurisdicción e invadiendo los que corresponden al Tribunal Constitucional. En suma, la no elevación de la cuestión es lesiva si el órgano judicial, subvirtiendo el sistema de fuentes y contraviniendo el sistema concentrado de justicia constitucional, decide la inconstitucionalidad de una norma con rango de ley sin someter ese juicio al Constitucional en un juicio incidental, desbordando su competencia jurisdiccional.

Un matiz o excepción muy relevante, como se ve, pues rompe el marco o parámetro ordinario en la materia, incluyendo un supuesto paralelo, con 
distintos efectos, en el que derechos fundamentales y cuestión de inconstitucionalidad salen íntimamente vinculados, al punto de poder darse la vulneración directa de aquellos en función del comportamiento judicial.

Asimismo, se trata de un encuadramiento de la lesión también trascendente. Es el art. 24.2 CE, por perturbarse el sistema de fuentes, el que queda comprometido en esos supuestos, al asociarse la desatención de este (inaplicar la ley sin cuestión de inconstitucionalidad) con el derecho a un proceso con todas las garantías, y no con la tutela judicial efectiva del art. 24.1 CE (aunque esta quede también afectada desde el prisma del derecho de defensa).

Finalmente, en estrecha relación con los contenidos de este trabajo, esta jurisprudencia proporciona una doctrina del Tribunal tuitiva e intensificadora de la cobertura de los derechos fundamentales, pues convierte el no planteamiento de la cuestión de inconstitucionalidad en una quiebra de derechos fundamentales.

Es importante precisar que el juez ordinario conculcaría este derecho fundamental solo en la hipótesis de haber reconocido dudas sobre la constitucionalidad de la norma rectora del caso y relevante para su resolución, habiéndola aplicado sin proceder a aquel planteamiento ante el Tribunal Constitucional y sin motivar adecuadamente esa decisión ${ }^{33}$.

Esta modificación en la doctrina constitucional tiene evidentes repercusiones positivas en la protección, cada vez más eficaz, de los derechos fundamentales de los individuos. Ante una duda, aunque mínima, de inconstitucionalidad del órgano judicial y la proposición de la parte del planteamiento de la misma, las garantías del derecho a la tutela judicial efectiva se han indiscutiblemente ampliado, al considerarse una vulneración susceptible de amparo constitucional la negativa al planteamiento sin una justificación razonada y razonable.

\section{OTRA CLASE DE «INTERFERENCIAS» O CONEXIONES ENTRE LA CUESTIÓN DE INCONSTITUCIONALIDAD Y EL RECURSO DE AMPARO CONSTITUCIONAL EN LA PROTECCIÓN DE LOS DERECHOS}

Para terminar con el análisis de los efectos de las decisiones del Tribunal Constitucional pronunciadas a raíz de una cuestión de inconstitucionalidad y su relación con la tutela de los derechos e intereses de los particulares, no se

33 Véanse, a este propósito, el FJ 5 c) de la STC 3/2016, de 18 de enero, y el FJ 2 de la STC 263/2015, de 14 de diciembre. 
puede dejar de hacer referencia a una peculiaridad presente en el ordenamiento jurídico español, en el que, como se ha apuntado, el TC puede ejercer una pluralidad de competencias.

Esta pluralidad de facultades y de vías de accesos a la jurisdicción constitucional ha provocado la «interferencia» entre los efectos de las sentencias recaídas en los procesos de control de constitucionalidad y los recursos de amparo en curso, señaladamente en aquellos casos en los que estos mismos traen origen de actos de aplicación de la ley declarada inconstitucional y nula. Estas circunstancias han llevado al Tribunal a fijar criterios de coordinación entre ambos procedimientos, de la que se deja constancia en estas páginas, vista la evidente conexión con el tema del presente trabajo de investigación.

\section{LOS EFECTOS DE LA INCONSTITUCIONALIDAD DE UNA LEY DECLARADA NULA POR SENTENCIA RECAÍDA EN UNA CUESTIÓN DE INCONSTITUCIONALIDAD SOBRE LOS RECURSOS DE AMPARO EN CURSO QUE TRAEN ORIGEN DE ACTOS DE APLICACIÓN DE LA LEY ANULADA: LA STC 159/1997 COMO PRONUNCIAMIENTO DE REFERENCIA}

No podría abordarse esta materia sin tomar en consideración la doctrina sentada por el Tribunal Constitucional español en Pleno en la STC 159/1997, de 2 de octubre, con ocasión de un recurso de amparo ${ }^{34}$.

El recurso se planteaba contra una sentencia de la Sala de lo Contencioso-Administrativo del Tribunal Superior de Justicia de Baleares y contra la confirmación administrativa de las autoliquidaciones correspondientes a un determinado ejercicio, practicadas por la actora en concepto de gravamen complementario de la tasa fiscal sobre los juegos de suerte, envite o azar, creado por el art. 38.2.2 de la Ley 5/1990, de 29 de junio, sobre medidas en materia presupuestaria, financiera y tributaria. La entidad recurrente denunciaba la violación del art. $14 \mathrm{CE}$, por un pretendido trato discriminatorio - así lo afirma la sentencia en su inicio, aunque, como aclarará luego, la queja se refiere, en realidad, a una supuesta desigualdad de trato del primer inciso de esa previsión constitucional, y no a la interdicción de discriminación del segundo- - A juicio de la demandante de amparo, el mencionado gravamen complementario suponía para ella, dedicada a la explotación de máquinas

34 La STC 159/1997 en examen es considerada la sentencia de referencia en cuanto a los efectos de una decisión que declare la inconstitucionalidad de una norma con fuerza de ley sobre un amparo que se encuentre pendiente de resolución también por Alzaga Villaamil et al. (2016: 730). 
recreativas tipo «B», una desigualdad inconstitucional en el trato en relación con el ofrecido por la ley respecto de las empresas dedicadas a otros juegos u otras actividades del sector del juego. También invocaba otros preceptos de la Constitución, algunos de ellos, como el art. 9.3 o el art. 31.1 CE, no susceptibles de amparo, como dirá el Tribunal después en su fundamentación jurídica.

Con posterioridad a la formalización de la demanda de amparo y su admisión a trámite, que tuvieron lugar ambas en el año 1994, el Tribunal Constitucional dictaría la STC 173/1996, de 31 de octubre, resolviendo diversas cuestiones de inconstitucionalidad acumuladas que concernían a aquel art. 38.2.2 de la Ley 5/1990, declarando inconstitucional y nulo el precepto, aplicado, como ha sido adelantado ya, en los autos de los que nacía el recurso de amparo. El motivo de la inconstitucionalidad — decía la sentencia anulatoria recién aludida en su FJ 5- era el de haber aplicado «retroactivamente, un aumento de la deuda tributaria que puede calificarse de no previsible y carente de suficiente justificación, lo que conduce a estimar que en este caso se ha producido una vulneración del principio de seguridad jurídica garantizado por el art. 9.3 CE».

La STC 159/1997 se ocupa de precisar el efecto que sobre el recurso de amparo en curso tiene la sentencia del Pleno de referencia, dictada en 1996, como se ha dicho, al versar tanto la una como el otro sobre el mismo precepto legal cuya inconstitucionalidad y nulidad fueron declaradas, y habida cuenta que, como reconocerá el Tribunal en el FJ 3 de la STC 159/1997, el objeto del recurso de amparo no se dirigía tanto contra la aplicación administrativa y judicial de aquel precepto controvertido (y declarado finalmente inconstitucional en momento posterior a su formalización), sino frente al contenido de la norma misma.

Tras diversas consideraciones para diferenciar el principio de igualdad del art. $14 \mathrm{CE}$ y el principio de igualdad tributaria del art. $31 \mathrm{CE}$ (no susceptible, este, de amparo, a diferencia del primero), o sobre otra de las quejas de la demanda (que invocaba el art. 24.1 CE por no haberse suscitado una cuestión de inconstitucionalidad como la parte requiriera, recordando que hacerlo es una prerrogativa exclusiva e irrevisable del órgano judicial ${ }^{35}$ ), la sentencia contiene los principios de constitucionalidad que resultan relevantes para el objeto de esta investigación.

El Tribunal dispone, en primer lugar, que en supuestos como el enjuiciado, en los que el problema de constitucionalidad ha sido resuelto previamente en el ámbito de un proceso de inconstitucionalidad (en el supuesto de

35 Subraya la importancia de este inciso, en la sentencia en análisis, también Fernández Farreres (2017: 290). 
referencia, en la STC 173/1996), si la declaración de inconstitucionalidad y nulidad se produjo por la vulneración de un precepto de la Constitución no susceptible de amparo, excluido por tanto de protección a través de ese procedimiento singular de tutela de derechos fundamentales, no cabe extender, sin más, al proceso de amparo los efectos de la sentencia declarativa de la inconstitucionalidad y nulidad del precepto. En otros términos, no tendrá efectos en el recurso de amparo tal declaración si se produce por resultar contraria la previsión normativa a un precepto constitucional ajeno al reconocimiento de los derechos fundamentales susceptibles de amparo constitucional, esto aunque exista un acto de aplicación de ese precepto (anulado por el Tribunal Constitucional de forma sobrevenida) en la controversia administrativa o judicial de la que trae origen el recurso. Si se prefiere, sensu contrario, la inconstitucionalidad declarada solo podrá incidir en el recurso de amparo cuando este proceso constitucional tenga en su base actos de aplicación de un precepto legal anulado por vulnerar derechos que pueden ser objeto de tutela en el amparo constitucional. De otro modo, avisa el Tribunal, se daría «un evidente exceso en el ejercicio de la jurisdicción de este Tribunal por el cauce del proceso de amparo, dado que se halla claramente delimitada en cuanto a los derechos y libertades susceptibles de tutela en dicho proceso constitucional por lo dispuesto en los arts. 161.1 b) y 53.2 C.E. y el art. 41.1 de nuestra Ley Orgánica ${ }^{36}$.

La consecuencia evidente de lo dicho, como también subraya la decisión ahora analizada, es que no siempre será posible invocar en el pronunciamiento resolutorio del amparo, con un carácter determinante y decisivo para la estimación o desestimación de la demanda, la previa sentencia emitida en otro proceso de inconstitucionalidad, por más que quede referida al mismo precepto legal que esté en cuestión en el recurso de amparo, ya que eso vendrá dado, o en su caso será excluido, en función del fundamento de la inconstitucionalidad declarada, esto es, de que el mismo radique o no en la vulneración de un derecho de carácter fundamental susceptible de amparo.

Tan clara es la idea como puede constatarse en un contraste entre la resolución constitucional que se destaca aquí y otras que ella misma cita (o algunas posteriores que también mencionaré), pues, por ejemplo, así como la STC 159/1997 no atiende a la declaración de inconstitucionalidad de la STC 173/1996 al resultar según ella lesivo el art. 38.2.2 de la Ley 5/1990, de 29 de junio, por vulneración del art. 9.3 CE (principio, por imperativo de los arts. 53.2 CE y 41.1 LOTC, que queda extramuros del proceso de amparo), en cambio, en las SSTC 223/1994, 224/1994, 225/1994, 226/1994, 284/1994,

36 STC 159/1997, de 2 de octubre, FJ 6. 
152/1995 y 145/1996, el amparo sí se otorgó y con remisión expresa a la sentencia del Pleno declarativa de la inconstitucionalidad, justo y precisamente porque la norma en cuestión en esos asuntos (anulada por la STC 179/1994, sobre el régimen de adscripción obligatoria a las Cámaras de Comercio, establecido por la base cuarta, apdo. $4^{\circ}$, de la Ley de 29 de junio de 1991) fue expulsada del ordenamiento jurídico por la contradicción de su régimen jurídico con (ahora sí) un derecho fundamental, en concreto el de asociación reconocido en el art. 22.1 CE, que, como es sabido, sí puede ser objeto de tutela en el procedimiento de amparo constitucional, al encontrarse ubicado en la sección primera del capítulo II del título primero de la Constitución.

En segundo lugar, la STC 159/1997 analiza otro orden de problemáticas. Según el art. 40.1 LOTC, la declaración de inconstitucionalidad en un proceso de control de constitucionalidad de la norma (como el que culminó, en el caso de referencia, con la STC 173/1996) no permite revisar un proceso fenecido mediante sentencia judicial con fuerza de cosa juzgada, dictada en aplicación de la ley luego anulada, pero antes de la sentencia constitucional declarativa de la inconstitucional. La única excepción a ello, según aquella previsión de la Ley Orgánica reguladora del Tribunal Constitucional, viene representada por los casos en los que esté comprometida la reducción de una pena o de una sanción, o una exclusión, exención o limitación de la responsabilidad $^{37}$. Al margen de ello, por tanto, la sucesiva declaración de inconstitucionalidad del precepto no incidirá en los procesos ya cerrados con la fuerza de la cosa juzgada.

La razón aducida por la jurisprudencia constitucional, como es de imaginar, reside en la garantía de la seguridad jurídica (art. 9.3 CE), que obliga a descartar una revisión general e indiscriminada de los pronunciamientos judiciales anteriores en razón de la inconstitucionalidad de la norma apreciada posteriormente. Si se quiere, dice el Tribunal, se persigue «un

37 Así lo evidencia también Camarero González (2019: 321).

La STC 39/2011, de 31 de marzo, recuerda e insiste en ese orden de cosas en que, dentro de dichas excepciones a la regla general, la sentencia del Tribunal que declara la inconstitucionalidad tiene efectos incluso sobre las situaciones jurídicas declaradas por sentencia con fuerza de cosa juzgada. Esto es, que la retroactividad establecida en el art. 40.1, in fine, de la LOTC «supone una excepción in bonum a lo prevenido, en términos aparentemente absolutos, por el art. 161.1 a) CE ("la Sentencia o Sentencias recaídas no perderán el valor de cosa juzgada”) [que] tiene su fundamento inequívoco, como no podía ser de otro modo, en la misma Constitución y, precisamente, en el art. 25.1 que impide, entre otras determinaciones, que nadie pueda sufrir condena penal o sanción administrativa en aplicación de normas legales cuya inconstitucionalidad se haya proclamado por este Tribunal Constitucional». 
equilibrio entre la estabilidad de las situaciones por así decir "judicialmente consolidadas", de conformidad con lo establecido en el segundo inciso del art. 161.1 a) $\mathrm{CE}$, y, de otro lado, ciertas excepciones, vinculadas con una posible revisión in bonum, como son todas las comprendidas en el indicado art. 40.1 LOTC. Y es obvio que éstas, en cuanto excepciones tasadas de la regla general, han de ser interpretadas restrictivamente para que sea respetado dicho equilibrio» ${ }^{38}$.

No obstante, precisa el Tribunal, a tal efecto por sentencia firme deberá entenderse, al objeto de lo dispuesto en el art. 40.1 LOTC, un proceso fenecido mediante sentencia con fuerza de cosa juzgada, siendo a ese propósito calificativo del todo irrelevante que dicha sentencia haya sido o no objeto de un ulterior recurso de amparo, y, en su caso, haya sido o no admitido y esté o no pendiente el dictado de una resolución sobre el mismo ${ }^{39}$.

Todo eso se desprendería, según el Tribunal Constitucional, del art. 161.1 a) CE, que no contiene una previsión de pérdida de valor de las sentencias recaídas en aplicación de la norma declarada posteriormente inconstitucional, limitándose a extender los efectos de esa declaración a la jurisprudencia que haya interpretado la norma. $Y$ es que, en efecto, aunque es verdad que refiriéndose al recurso de inconstitucionalidad y no a otros procedimientos, el precepto constitucional literalmente dice: «La declaración de inconstitucionalidad de una norma jurídica con rango de ley, interpretada por la jurisprudencia, afectará a ésta, si bien la sentencia o sentencias recaídas no perderán el valor de cosa juzgada».

Ciertamente, no se encuentran razones para alcanzar una conclusión distinta cuando la declaración de inconstitucionalidad tenga origen en el proceso incidental de una cuestión de inconstitucionalidad; y esto, más aún, cuando dicha problemática queda aclarada del todo a tenor de lo dispuesto en la STC 159/1997 que se acaba de examinar. En efecto, esta decisión contiene y afirma el criterio descrito al resolver sobre los efectos que posee en un proceso de amparo una sentencia que fue dictada anteriormente en una cuestión de inconstitucionalidad (en realidad, en varias acumuladas).

En definitiva, salvo que se trate de los procesos penales o contencioso-administrativos relativos a un procedimiento sancionador, la declaración de inconstitucionalidad, ex art. 40.1 LOTC, no da lugar a la revisión de los procesos ya fenecidos por sentencia con fuerza de cosa juzgada, siendo entonces

38 STC 159/1997, de 2 de octubre, FJ 7 B).

39 En ese mismo sentido se han pronunciado sentencias posteriores, como la STC 3/2016, de 18 de enero, FJ 2 a). La muy reciente STC 11/2020, de 28 de enero, precisa el concepto de «firmeza» referido a las resoluciones judiciales en su FJ 9 A). 
irrelevante que se haya hecho en ellos aplicación de las leyes declaradas inconstitucionales por el Tribunal Constitucional.

En tercer lugar, y siempre en relación con los efectos de este tipo de declaraciones en los procesos de amparo en curso, añade el Tribunal que no podrá apreciarse la lesión del art. 24.1 CE en esta tipología de casos de declaración sucesiva de inconstitucionalidad. Sencillamente porque la resolución recurrida, dice con evidente buen criterio el Tribunal, no desvela una desatención del sistema de fuentes establecido (art. 1.7 CC), sino, justamente, su aplicación y debido respeto, ya que el precepto legal luego anulado estaba integrado entonces en el ordenamiento jurídico y no era obligatorio para el juez o Tribunal que la aplicó, a tenor de la doctrina existente sobre las cuestiones de inconstitucionalidad, haber procedido necesariamente a su planteamiento.

Con esa suma de criterios enunciados, el Tribunal consideró en la STC 159/1997 que no había lesión alguna que fundase el otorgamiento del amparo, particularmente que no cabía resolver el recurso de amparo por remisión a lo juzgado en la STC 173/1996, en la que se dio la declaración de inconstitucionalidad y nulidad del art. 38.2.2 de la Ley 5/1990, pero por vulneración del principio de seguridad jurídica que consagra el art. 9.3 CE, precepto no susceptible de amparo.

\section{LOS VOTOS PARTICULARES A LA STC 159/1997 Y UNAS REFLEXIONES A MODO DE SÍNTESIS}

La STC 159/1997 contó con varios votos particulares. En el formulado por el magistrado don Fernando García-Mon y González-Regueral se plantea, a mi modesto parecer, un interesante debate, que pone en contraste el art. 40.1 y el art. 38, ambos de la LOTC. Así como el primero, según se ha dicho, impide la revisión de las sentencias dictadas en procesos fenecidos (salvo en las excepciones penales o sancionatorias ya descritas, en las que la reapertura del proceso tras la declaración de inconstitucionalidad podría acarrear un beneficio - que el art. 40.1 LOTC atiende- para el interesado frente a la pena, sanción o responsabilidad impuestas), el art. 38 LOTC, que invocaba el magistrado discrepante, dispone el carácter de cosa juzgada de la sentencia que declara la inconstitucionalidad, su vinculación para todos los Poderes Públicos y la producción de efectos generales desde la publicación en el diario oficial. El juez constitucional deducía de las prescripciones de este último precepto la imposibilidad, también para el Tribunal Constitucional y desde la fecha de la publicación de la STC 173/1996 (que declaró, recuérdese, la inconstitucionalidad de la norma controvertida), de desatender la nulidad de la norma en las sentencias pendientes del amparo constitucional. 
A su detenido y razonado criterio, el art. 38.1 LOTC resuelve el problema en sentido distinto al acogido por la mayoría del Tribunal. En su voto particular se lee:

Todos los Poderes Públicos, y por tanto también y con mayor razón el Tribunal Constitucional, están vinculados desde el 3 de diciembre de 1996, fecha de su publicación en el B.O.E., por lo resuelto en la STC 173/1996 y, por consiguiente, esa vinculación nos impide mantener a finales de 1997 que un precepto ya inexistente, continúe siendo el único sustento de la Sentencia que revisamos. Revisión que se hace como si el precepto aplicado siguiera vigente y la Sentencia tuviera que encuadrarse - como se hace - en los casos previstos para el recurso de amparo en los arts. 53 y siguientes de la LOTC, prescindiendo de que a ello se antepone lo dispuesto en el art. 38.1 de la propia Ley.

Obviamente, postular esa posición pasaba, de modo inevitable, por entender que el proceso judicial no había fenecido. $\mathrm{O}$, dicho de otro modo, que la interposición del recurso de amparo evitaría considerarlo cerrado. A su parecer, por tanto, es el plazo de caducidad del amparo (art. 44.2 LOTC) el que debe haber vencido, sin formalización del recurso, para que pueda operar el régimen del art. 40.1 LOTC, que fijaría una excepción a aquello general del art. 38 de la misma Ley.

No es cuestión baladí, como se ve, por más que tenga efectos únicamente en los procesos penales y sancionatorios indicados. $Y$ no lo es porque, a mi juicio, el parámetro que sigue la jurisprudencia constitucional tras pronunciamientos como el comentado no es tanto que el proceso haya o no fenecido, como del art. 40.1 LOTC se seguiría, sino, antes bien, que la norma declarada inconstitucional (aunque el proceso haya fenecido por no estimarse vivo durante el plazo de caducidad del amparo) afectara o no a derechos fundamentales. Siendo ese el enfoque correcto tras la lectura de la jurisprudencia constitucional que se ha destacado en este punto, cabe como mínimo dudar de la preferencia que se otorga en esta tipología de casos, por razón de la materia, al art. 40.1 LOTC, frente al régimen general del art. 38.1 LOTC, que impone los efectos generales o erga omnes de la sentencia recaída en el proceso constitucional, sin matices, desde su publicación, esto es, sin distinguir que la misma declare vulnerados unos u otros preceptos constitucionales, los relativos a derechos fundamentales o los que cuenten con otro contenido diferente.

El segundo voto particular, formulado por el magistrado don Manuel Jiménez de Parga y Cabrera, y al que se adhirió el magistrado don Rafael de Mendizábal Allende, también manifestó su preocupación por la no extensión al amparo en curso de lo resuelto en la STC 173/1996. Más allá de defender una redefinición de la cuestión de inconstitucionalidad —en razón de la 
negativa a plantear ese procedimiento por parte del órgano judicial que dictó la sentencia recurrida ${ }^{40}$ - se detiene, con la finalidad de defender una solución discrepante, en el art. 55.2 LOTC. Señala que de tal precepto se desprende que ha de concederse el amparo siempre que la ley aplicada para resolver un asunto lesione "derechos fundamentales o libertades públicas» y que la proposición entrecomillada (que contiene la citada previsión de la Ley Orgánica) incluye (a su parecer) la seguridad jurídica, al ser un principio configurador o soporte estructural de la tutela judicial efectiva (derecho fundamental reconocido y protegido por el art. 24.1 CE, susceptible de amparo constitucional) y, asimismo, el marco esencial de las libertades públicas que los ciudadanos no disfrutan cuando aquella seguridad jurídica falta. Concluye el magistrado que, así las cosas, el soporte estructural de aquellos derechos (la citada seguridad jurídica) no puede tener menor protección constitucional que estos (lo que habría permitido ad casum extender los efectos de la declaración de inconstitucionalidad de la norma al recurso de amparo que se resolvía). En definitiva, una construcción sin duda tuitiva de los derechos de los particulares desde un enfoque material, pero también, a mi parecer, de complicado soporte, toda vez que no parte del texto normativo del art. 55.2 LOTC, sino, acaso, de esa regulación, pero interpretada conforme a una determinada lectura de la función de la seguridad jurídica como instrumento que otorga virtualidad y sostén estructural o de sistema a los derechos fundamentales. No se quiere, evidentemente, en esta sede negar la viabilidad de la construcción, pero no puede tampoco eludirse esa dificultad concurrente, que obligaría a justificar ex Constitutione la premisa que la sostiene (el pretendido soporte ofrecido por la seguridad jurídica a los derechos fundamentales).

El tercer y último voto particular fue formulado por el magistrado don Vicente Gimeno Sendra. En un sentido en parte apuntado ya en los restantes votos, y que por lo tanto aconseja evitar reiteraciones, se subraya que los efectos de una sentencia constitucional alcanzan a todos los Poderes Públicos, de modo que también al propio Tribunal, sobre todo si no nos encontramos en el marco de aplicabilidad del art. 40.1 LOTC, como a su parecer sucede cuando ha sido interpuesto un recurso de amparo (criterio que comparte con el

40 Sostiene que, de manera acorde con la doctrina del Tribunal Europeo de Derechos Humanos, esa redefinición debería pasar "por un entendimiento de la cuestión que, reservada en su planteamiento a los Tribunales ordinarios, obligara a éstos a justificar adecuadamente su negativa a suscitarla y, en lo que ahora importa, permitiera la modulación de los efectos establecidos en el art. 40.1 LOTC a los fines de que, interesada — sin éxito - la promoción de una cuestión, la posterior declaración de inconstitucionalidad de la norma pudiera desplegar su eficacia en el proceso concluido por Sentencia». 
primer voto particular, aunque no con argumentos idénticos, como puede verse en la parte final de su texto). De otro lado, afirma que la sentencia impugnada, al haber aplicado un precepto legal que posteriormente fue declarado inconstitucional, no puede considerarse fundada en derecho. A su juicio, en fin, y en mi opinión esto sería lo más relevante, visto el régimen jurídico del art. 38.1 LOTC, dice, podría estar estableciéndose «una peligrosa excepción a los efectos erga omne et omnes de las Sentencias de inconstitucionalidad», apuntando con ello su oposición a la diferenciación que la mayoría hace a tenor del precepto constitucional que llegue a fundar la inconstitucionalidad de la norma.

Ha podido observarse en la exposición anterior que, dicho ahora a modo de síntesis, el Tribunal puede en ocasiones, como es ejemplo el antes descrito, no estimar recursos de amparo pese a estar las resoluciones impugnadas fundadas en normas declaradas inconstitucionales con posterioridad al dictado de la recurrida y a la interposición o admisión de la demanda del proceso constitucional. Se diría, de ese modo, que se da una especie de continuidad potencial de los efectos de la norma, pese a haber sido desterrada del derecho por su inconstitucionalidad. Desde esta perspectiva, no podrá entonces afirmarse que el recurso de amparo integre un propósito de evitar actos de aplicación de leyes contrarias a la Constitución, sino solo, a lo sumo, de aquellos actos de aplicación de leyes que se declaren contrarias a la consagración constitucional de los derechos fundamentales.

Los mismos criterios ya analizados han sido reiterados por el Tribunal en pronunciamientos posteriores en los que el Constitucional no ha podido extender los efectos de la declaración de inconstitucionalidad anterior al amparo en curso, por no fundarse el vicio en la vulneración de un derecho fundamental reconocido en los arts. 14-29 y $30.2 \mathrm{CE}^{41}$.

41 Se trata de las decisiones indicadas a continuación. La STC 183/1997, de 28 de octubre, podría considerarse de la misma serie que la STC 159/1997, y a ella expresamente se remite, por gravitar la controversia sobre la misma norma anulada, al igual que puede verse en las SSTC 71/1998, de 30 de marzo; 137/1998, de 29 de junio; 36/1999, de 22 de marzo; 84/1999, de 10 de mayo; 200/1999, de 8 de noviembre, y 111/2001, de 7 de mayo, todas afectantes a la misma norma y equiparable controversia relativa al 38.2.2 de la Ley 5/1990. Algo muy similar sucede con la STC 55/1998, de 16 de marzo, aunque no estuviera directamente a debate la aplicación del art. 38.2.2 de la Ley 5/1990, sino el art. 77 de la Ley de Presupuestos Generales para 1991 al que a aquel se remitía.

No cambian la doctrina aludida las SSTC 91/2007, de 7 de mayo; 6/1998, de 13 de enero; 91/2007, de 7 de mayo; 84/2008, de 21 de julio; 122/2008, de 20 de octubre; $107 / 2019$, de 30 de septiembre. 


\section{ALGUNAS CONSIDERACIONES CONCLUSIVAS}

Además de las conclusiones que se han ido apuntando en los distintos epígrafes, es oportuno, a este punto, evidenciar algunas consideraciones finales.

En primer lugar, y por lo que concierne a la nueva regulación introducida con la modificación de la LOTC en 2007: la reforma satisfizo a la mayoría de la doctrina, que observa en la modificación legislativa un avance decisivo para la tutela de los derechos e intereses de los individuos, especialmente de los sujetos comprometidos en el proceso ordinario en el que se origina la cuestión. Como recuerda muy claramente López Ulla (2007: 199):

[...] afirmar que las partes del proceso a quo son ajenas al juicio [del TC] es negar lo evidente. [...]. En este sentido podríamos hablar, como hace la doctrina italiana, de un cierto carácter híbrido de este proceso constitucional pues si es bien claro que éste tiene por objeto el examen objetivo de la constitucionalidad de una ley — con independencia de los intereses enfrentados en el proceso a quo- este interés público no contradice ni niega su posible utilidad como instrumento de defensa de derechos particulares.

Puede concluirse, comprobando las estadísticas ${ }^{42}$ y apoyándonos en las valoraciones de ilustres juristas ${ }^{43}$, que la cuestión de inconstitucionalidad ha llevado efectivamente a cabo (y no puede dudarse que así seguirá ocurriendo en el futuro) una labor crucial en la protección de los derechos e intereses subjetivos en supuestos en los que su eventual lesión provenga directamente de una normativa con fuerza de ley. Es imposible, e incluso incorrecto, en efecto, olvidar la concurrencia de un interés subjetivo de las partes del proceso a quo, que no puede ser por completo soslayado o ajeno en la decisión del Tribunal

En cambio, pueden mencionarse, entre las decisiones que resolvieron recursos de amparo por directa remisión a una sentencia declarativa de la inconstitucionalidad de una norma con rango de ley, las siguientes sentencias: 46/2008, de 10 de marzo, la STC 20/2017, de 27 de febrero, 40/2017, de 24 de abril; 70/2017, de 5 de junio; 74/2017, de 19 de junio; 83 y 84/2017, de 3 de julio; 104/2017, de 18 de septiembre; 125/2019, de 31 de octubre. La cuestión de inconstitucionalidad se ha utilizado principalmente invocando la vulneración de los preceptos constitucionales reconocedores de derechos fundamentales (pueden consultarse, a este respecto, las Memorias anuales del TC).

Siempre hablando de datos, y en consideración del tema desarrollado en este capítulo, hay que registrar un incremento en la participación de las partes del proceso a quo en la fase ante el Constitucional. Pueden citarse, como ejemplos recientes en los que las partes se han personado en la fase ad quem, las SSTC 20/2020, de 10 de febrero, A 13; 160/2019, de 12 de diciembre, A 11; 152/2019, de 25 de noviembre AA 8-12-13-14; 23/2017, de 16 de febrero, A 9.

43 López Ulla (2007: 200-201). 
Constitucional, pues esta será determinante para la resolución de la litis en uno u otro sentido, con evidentes efectos sustantivos.

En suma, puede considerarse que las modificaciones introducidas con la LO 6/2007, de 24 de mayo, contribuyen a reforzar la naturaleza (también) subjetiva de la cuestión de inconstitucionalidad, alejándola de la más clásica concepción exclusivamente objetiva que veía este tipo de proceso constitucional como un cauce abstracto de depuración del ordenamiento jurídico. Aunque el objeto principal de la cuestión de inconstitucionalidad siga centrado en el juicio abstracto de constitucionalidad de la norma con rango de ley, la participación de las partes en el proceso ad quem abre las puertas y refuerza indudablemente la dimensión subjetiva del procedimiento, así como los efectos subjetivos de la resolución del mismo, afianzando tanto aquella y estos como el derecho de defensa de los ciudadanos y la relevancia de sus intereses particulares, sustanciados en el proceso judicial, en la mirada del Tribunal Constitucional.

Todas estas consideraciones encuentran un importante y ulterior refuerzo, de un lado, en la evolución de la jurisprudencia constitucional en tema de violación del art. $24 \mathrm{CE}$ por parte del juez ordinario que decida no plantear una cuestión de inconstitucionalidad cuando esta sea propuesta a instancia de parte, y esa parte no reciba la debida justificación por parte del órgano jurisdiccional, o este exceda sus competencias; y, de otro, en la comprobación de los efectos ad extra de las cuestiones de inconstitucionalidad para la protección de los derechos fundamentales de los particulares en aquellos casos en los que existan «interferencias» entre la resolución de una cuestión que declare la inconstitucionalidad de una norma con rango de ley y los recursos de amparo en curso (siempre que se den las circunstancias y con las limitaciones que se han analizado supra). En efecto, ambos ámbitos demuestran que la cuestión de inconstitucionalidad ha integrado realmente la faceta tuitiva, que ha sido por largo tiempo desatendida por la doctrina, con aquella otra primaria y central (la objetiva) de garantizar la superioridad de la Constitución y la eliminación de las leyes inconstitucionales. Y que, incluso y más allá de esto, el control incidental de constitucionalidad de las leyes tiene la virtud de proyectar los efectos de esta dimensión subjetiva sobre o a través de otro proceso constitucional, como es el recurso de amparo.

Como última consideración, quisiera resaltar que el control incidental de constitucionalidad, gracias a la conciliación entre las dos dimensiones de la justicia constitucional a las que se ha aludido múltiples veces, no solo determina la protección de los derechos fundamentales, sino que, sobre todo, opera esa tutela de un modo cualitativamente diferente con respecto a aquella garantizada por los órganos de la jurisdicción ordinaria o por el mismo juez constitucional a través del amparo constitucional. Y es que el carácter «híbrido» de la 
cuestión de inconstitucionalidad, que fusiona y conecta elementos del control concreto y del abstracto, del modelo difuso y del concentrado, permite a los tribunales constitucionales proporcionar una protección de los derechos fundamentales que - se podría decir - integra lo subjetivo y lo objetivo, pues enjuicia la constitucionalidad de una norma en el momento de su concreta aplicación, desplegando así un control abstracto y a su vez contextualizado en la vivencia normativa del caso concreto. Todo esto permite a la jurisdicción constitucional realizar una ponderación de los derechos e intereses involucrados que supera las limitaciones de un enjuiciamiento ad casum y que cuenta con efectos erga omnes, lo cual, por si fuera poco, se produce con la mediación y la colaboración de otro órgano del Estado, absolutamente imparcial y especialmente cualificado en esta tarea, como es el Poder Judicial, garante natural de los derechos fundamentales.

\section{Bibliografía}

Alzaga Villaamil, Ó. et al. (2016). Derecho politico español: Según la Constitución de 1978. Tomo II: Derechos fundamentales y órganos del Estado. Madrid: Editorial Universitaria Ramón Araces.

Benvenuti, L. (2016). La via francese alla giustizia costituzionale. Ideologia, politica e «dialogo» tra Corti. Napoli: Edizioni Scientifiche Italiane.

Camarero González, G. J. (2019). El recurso de amparo. En A. Zárate Conde (coord.). Derecho Constitucional (pp. 309-334). Madrid: Editorial Universitaria Ramón Araces.

Castellá Andreu, J. M. y Expósito Gómez, E. (1999). La intervención de las partes del juicio a quo en la cuestión de inconstitucionalidad. El art. 37.2 LOTC y la incidencia de la STEDH de 23 de junio de 1993. Teoría y realidad constitucional, 4, 293-316. Disponible en: https://doi.org/10.5944/trc.4.1999.6490.

Cavino, M. (2014). Lezioni di giustizia costituzionale francese. Napoli: Editoriale Scientifica.

Corzo Sosa, E. (1998). La cuestión de inconstitucionalidad. Madrid: Centro de Estudios Políticos y Constitucionales.

Cruz Villalón, P. (1987). La formación del sistema europeo de control de constitucionalidad (1918-1939). Madrid: Centro de Estudios Constitucionales.

Escobar Fernández, C. (1993). Sentencia del Tribunal Europeo de Derechos Humanos, de 23 de junio de 1993, en el asunto Ruiz-Mateos contra España. Revista Española de Derecho Internacional, 45 (2), 573-580.

Fernández Farreres, G. (2017). Inaplicación judicial de la Ley por razón de primacía del Derecho de la Unión Europea y derechos fundamentales a la tutela judicial efectiva y a un proceso con todas las garantías: estado de la cuestión en jurisprudencia constitucional. En J. C. Laguna de Paz, Í. Sanz Rubiales e I. De los 
Mozos Touya (coords.). Derecho administrativo e integración europea: estudios en homenaje al profesor José Luis Martínez López-Muñiz (pp. 287-306). Madrid: Reus.

Fernández Segado, F. (2005). La justicia constitucional ante el siglo XXI: la progresiva convergencia de los sistemas americano y europeokelseniano. Pensamiento Constitucional, 11, 19-75.

Gallardo Castillo, M. J. (1994). RUMASA ante el Tribunal Europeo de Derechos Humanos. Revista Española de Derecho Administrativo, 84, 613-629.

García Roca, J. (1992). El planteamiento de la cuestión de inconstitucionalidad por el juez ordinario: el caso del juez civil. Revista de las Cortes Generales, 27, 101138. Disponible en: https://doi.org/10.33426/rcg/1992/27/238.

- (2007). La muy discrecional doctrina del margen de apreciación nacional según el Tribunal Europeo de Derechos Humanos: soberanía e integración. Teoría y Realidad Constitucional, 20, 117-143.

- (2010). El margen de apreciación nacional en la interpretación del Convenio Europeo de Derechos Humanos: soberanía e integración. Madrid: Civitas-Thomson Reuters.

González Jiménez, M. (1996). La admisión a trámite en las cuestiones de inconstitucionalidad. Revista de las Cortes Generales, 39, 211-239. Disponible en: https:// doi.org/10.33426/rcg/1996/39/881.

Herrero-Tejedor, F. (2000). La intervención de las partes en la cuestión de inconstitucionalidad. Repertorio Aranzadi del Tribunal Constitucional, 3, 15-43.

López-Fragoso Álvarez, T. (1991). La falta de legitimación de las partes de un proceso para solicitar del órgano jurisdiccional el planteamiento de la cuestión de inconstitucionalidad ante el Tribunal Constitucional. La Ley, 1, 1064-1067.

López Ulla, J. M. (2000). La cuestión de inconstitucionalidad en el derecho español. Madrid: Marcial Pons.

- (2007). La cuestión de inconstitucionalidad tras la reforma de la Ley Orgánica 6/2007 del Tribunal Constitucional. En P. Pérez Tremps (coord.). La reforma del Tribunal Constitucional. Actas del V Congreso de la Asociación de Constitucionalistas de España (pp. 177-216). Valencia: Tirant lo Blanch.

Medina Guerrero, M. (2000). Los procesos de control de la constitucionalidad de la ley (II): El control indirecto. La sentencia en los procesos de control de constitucionalidad. En F. Caamaño Domínguez, A. J. Gómez Montoro, M. Medina Guerrero y J. L. Requejo Pagés (coords.). Jurisdicción y procesos constitucionales (pp. 49-78). Madrid: McGraw-Hill.

Montilla Martos, J. A. (1994). Defensa judicial versus ley singular de intervención (comentario a la sentencia del Tribunal Europeo de Derechos Humanos de 23 de junio de 1993 sobre el caso Rumasa). Revista Española de Derecho Constitucional, 40, 291-321.

Pérez Gordo, A. (1980). La legitimación activa de las partes en la cuestión de inconstitucionalidad. Revista Jurídica de Catalunya, 3, 759- 770.

Pérez Tremps, P. (1985). Tribunal Constitucional y Poder Judicial. Madrid: Centro de Estudios Constitucionales. 
Requejo Rodríguez, P. (2015). Cuestión de inconstitucionalidad y tutela judicial efectiva. Revista de Estudios Jurídicos, 15, 1-16. Disponible en: https://doi. org/10.17561/rej.v0i15.3156.

Ribas Maura, A. (1991). La cuestión de inconstitucionalidad. Madrid: Civitas.

Rubio Llorente, F. y Aragón Reyes, M. (1981). La jurisdicción constitucional. En A. Predieri y E. García de Enterría (dirs.). La Constitución española de 1978. Estudio sistemático (pp. 798-863). Madrid: Civitas.

Rubio Llorente, F. y Jiménez Campo, J. (1998). Estudios sobre jurisdicción constitucional. Madrid: McGraw-Hill.

Ruggeri, A. y Spadaro, A. (2019). Lineamenti di Giustizia costituzionale. Torino: Giappichelli Editore.

Vidal Fueyo, M. D. C. (2013). Ruiz Mateos c. España (STED de 23 de junio de 1993): Las garantías del proceso equitativo ante la jurisdicción constitucional. En J. M. Sánchez Tomás, M. Beladiez Rojo y R. Alcácer Guirao (coords.). Conficto y diálogo con Europa: las condenas a España del Tribunal Europeo de Derechos Humanos (pp. 131-152). Cizur Menor: Civitas Thomson Reuters.

Villaverde Menéndez, I. (2003). Algunas reflexiones acerca de la cuestión de inconstitucionalidad. Cuadernos de Derecho Público, 18, 241-258.

Viver Pi-Sunyer, C. (1999). El auto de planteamiento de la cuestión de inconstitucionalidad. Cuadernos de Derecho Público, 7, 97-109.

Zagrebelsky, G. y Marcenò, V. (2018). Giustizia costituzionale. Bologna: Il Mulino. 